\title{
Heat Transfer Measurements with Temperature Oscillation Method
}

\author{
Stanislav Solnař, Martin Dostál, Tomáš Jirout \\ Department of Process Engineering, Czech Technical University in Prague \\ Technická 4, Prague, Czech Republic \\ stanislav.solnar@fs.cvut.cz; martin.dostal@fs.cvut.cz; tomas.jirout@fs.cvut.cz
}

\section{Extended Abstract}

The temperature oscillation (TOIRT) method for convective heat transfer measurement was presented by authors Wandelt and Roetzel [1] in late 90's. This transient method is based on measuring the wall temperature with IR camera. The wall temperature depends on two main factors: heat transfer coefficients on both sides of the wall, and the sine modulated heat flux. Local temperatures, measured by the IR camera, show a sinusoidal tendency with a phase delay to the sinusoidal heat flux. This phase delay is in a direct relationship with heat transfer coefficient in every measured point.

The TOIRT method was extensively investigated and applied by Freund [2] in his dissertation thesis. In addition to verification experiments, he performed a theoretical and sensitivity analysis of this method. His other articles regarding the TOIRT method deal with heat transfer in plate heat exchangers [3] or with heat transfer in spray cooling systems [4].

In our experiments a two channel function generator was used. A sinusoid is formed in the first channel and this signal is connected to voltage supplies and halogen flood lights, which emit the heat energy to the measured wall. The second channel of the generator triggers the IR camera in precise time steps. The temperature fields obtained from IR camera are saved in PC and processed in MATLAB software to detect the phase delay and evaluate the heat transfer coefficients.

We performed a flow of water in the tube experiment as a validation test of the method, and evaluated the experimental data into the classical very well-known Nusselt and Reynolds numbers dependence. The Reynolds number (based on the mean velocity in the tube) power was 0.79 and the geometric constant corresponded (with a $12 \%$ error) to the known Dittus-Boelter correlation for heat transfer of fluid flow in the tube. Another validation experiment consisted in heat transfer between the plain wall and the impinging jet, where we identified three areas of the fluid flow (stagnant and transition area - Reynolds power about 0.55 , and flow area along the wall - Reynolds power about 0.8 ), which perfectly correspond with the literature.

In the case of agitated vessel experiments with a flat bottom, we have focused on heat transfer at the bottom and at the wall of the vessel equipped with standard impellers (6PBT45 or Rushton turbine). At the bottom of an agitated vessel Reynolds number (based on rotation speed of impeller) power was about 2/3, which can be very often seen in the literature. In the case of the wall region of an agitated vessel the Reynolds number power about was $1 / 3$, which points to a very complex flow in this area.

The TOIRT method shows good experimental results compared to the literature and in summary it can be characterized as contactless and fast method for convective heat transfer measurement with an option to change a spatial resolution and without any dependence on the fluid in which the heat transfer takes place.

\section{Acknowledgements}

This work is supported by the Grant Agency of the Czech Technical University in Prague, grant No. SGS 019/18.

\section{References}

[1] M. Wandelt and W. Roetzel, "Lockin thermography as a measurement technique in heat transfer," in Proceedings of the Quantitative Infra-Red Thermography, Pizza, Italy, pp. 189-194, 1997.

[2] S. Freund, "Local Heat Transfer Coefficients Measured with Temperature Oscillation IR Thermography," Ph.D. Dissertation, Helmut-Schmidt-Univ., Hamburg, Germany, 2008.

[3] S. Freund and S. Kabelac, "Investigation of local heat transfer coefficients in plate heat exchangers with temperature oscillation IR thermography and CFD," Int. J. of Heat and Mass Transfer, vol. 53, pp. 3764-3781, 2010. 
[4] S. Freund, A. G. Pautsch, T. A. Shedd and S. Kabelac, "Local heat transfer coefficients in spray cooling systems measured with temperature oscillation IR thermography," Int. J. of Heat and Mass Transfer, vol. 50, pp. 1953-1962, 2010 . 